\title{
Control Banding: The New Approach of Risk Assessment in Malaysia
}

\author{
Ts. Hazlina Yon \\ Department of Occupational Safety and Health, Malaysia \\ *Corresponding author: hazlina@mohr.gov.my
}

\begin{abstract}
Article History
Received: January 20, 2020

Received in revised form: March 11, 2021 Accepted: March 15, 2020

Published Online: June 30, 2021
\end{abstract}

\begin{abstract}
The control banding method is a simplified risk assessment for chemical handling tasks. It has been integrated into Malaysian risk assessment tool called Simple Risk Assessment and Control (SiRAC). A brief introduction of SiRAC is narrated with small medium enterprises (SMEs) as the initial target audience. SMEs are lacking in occupational safety and health knowledge and resources yet contributed 66\% to employment in Malaysia. The purpose of this article is to elaborate on this new tool of risk assessment. There are seven steps in the assessment where bands of hazards grouped with bands of exposure to select one of the appropriate four control approaches. Appropriate control guidance sheet will be selected based on task under each approach. SiRAC has its limitation in scope of coverage and only chemicals in liquid or solid forms can be assessed. SiRAC is using hazard classification introduced by the Globally Harmonized System of Classification and Labelling of Chemicals (GHS) which has been embedded in the local legislation. Person to conduct SiRAC should be trained by approved training provider. SiRAC Online is under development to complement the tool. Despite its limitation and anticipated weaknesses, SiRAC is expected to be sufficient as an initial tool to assist SMEs in chemical risk management in Malaysia.
\end{abstract}

Keywords: Control banding approach, small medium enterprises, risk assessment, SiRAC

\subsection{INTRODUCTION}

Chemical management status in small and medium enterprises (SME) is known to be poor around the globe. According to the International Labor Organization (ILO) ( ILO, 2020), globally over 20 million workers employed in the chemical industries. Improper use of chemicals can cause adverse health effects to its users. Many literature reviews (Khoo T.H. et. al, 2011) concluded that there exist a big risk gap between occupational safety and health between SME and large companies. However, SME plays a very important role in Malaysia economy. SMEs represent $98.5 \%$ of the business population in Malaysia while contributing $38.3 \%$ to overall GDP, $17.3 \%$ to total exports and $66.2 \%$ to overall employment in 2018 (SME Corp, 2020). Through enforcement activities conducted by the Department of Occupational Safety and Health (DOSH) Malaysia, SMEs are found to be lacking in occupational safety and health (OSH) knowledge, lacking in financial support to implement OSH programmes as well as lack of proper coordination on OSH (Department of Occupational Safety and Health, 2020). As OSH is not well-managed by SMEs, a ready-made solution to manage risk at work with little expert involvement would be welcomed among the SMEs.

According to SME Corporation (2020), SMEs are categorized based on either their annual sales turnover or the number of full-time employees. For manufacturing sector, SMEs are defined as companies with a sales turnover of not more than RM50 million or less than 200 full-time employees while for services and other sectors, SMEs are defined as companies with a sales turnover not more than RM20 million or less than 75 full-time employees. This is graphically shown in Figure 1. 


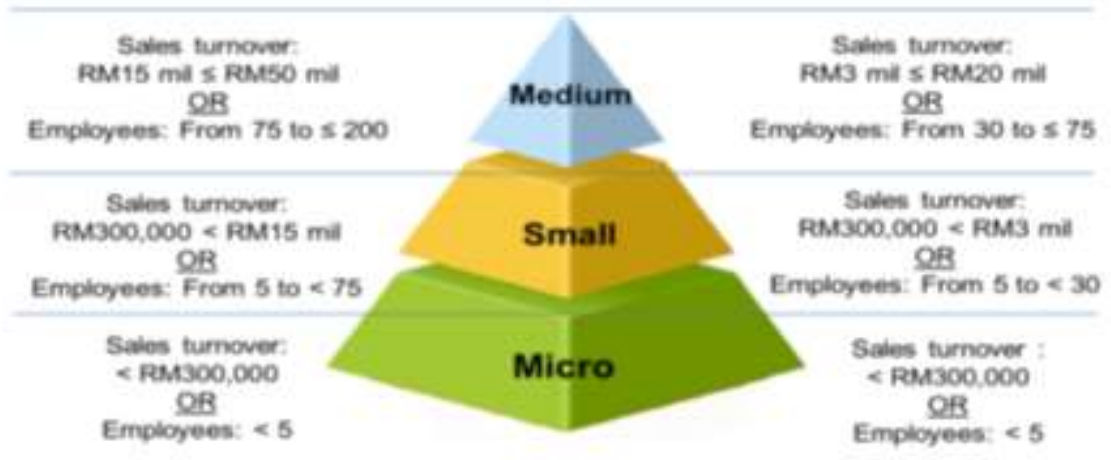

Figure 1: Graphical definition of small medium enterprises (SME Corp, 2020)

Further statistics from the ILO, estimates that yearly there is around 2.3 million men and women around the world succumb to work-related accidents and diseases; and these accidents and diseases increased annually (ILO, 2020). The most death among workers are due to work-related diseases with diseases due to hazardous substsance estimated to render 651, 279 deaths per year. For employers in SMEs, compliance to legislations is still lacking and it is not an easy task for them. Tools have been developed in various countries to support the SMEs in their compliance. One of the tools developed is control banding. Control banding is a simplified qualitative risk assessment system for chemical handling tasks. It encompasses of categories of hazards and categories of exposure potential to evaluate a risk. The risk estimated will subsequently be used to recommend levels of controls ( (Zalk DM \& Nelson DI, 2008).

The objective of Control banding (CB) in the world was originally started by pharmaceutical industry in the late 1980 's to enable users to work safely with new chemicals which has little information or no toxicity information (Zalk et. al., 2008). The new chemicals were then classified into bands based on other studied materials' toxicity and anticipated safe work practices, taking into consideration exposure assessments. For nanomaterials which do not have any toxicological and exposure data, application of $\mathrm{CB}$ has become popular recently and is very useful for estimation of risk.

According to Zalk et. al (2008), CB tool furnish simplified solutions for controlling worker exposures to contaminants found at the workplace. Modern CB models were then developed for non-experts to provide hazard and exposure potential information. As a result, control approach and recommendations will be given to the non-experts to assist in workplace improvement. Traditional industrial hygiene method of monitoring is made easier with the introduction of CB. CB has been applied in SMEs within developing countries since its inception and while large enterprises integrate it within their chemical safety programmes. CB may be a useful strategy for assessing and controlling occupational hazards associated with chemical exposures at the workplace for those chemicals which do not have occupational exposure limits.

CB is increasingly applied globally especially after the United Kingdom incorporated CB into its legislation i.e. The Control of Substances Hazardous to Health (COSHH). The United Kingdom Health and Safety Executive (HSE) later on developed the CB approach to workplace risk management called COSHH Essentials which is also available online (Health and Safety Executive, 2020). CB has also been recognized internationally by the ILO through its collaboration with the World Health Organisation (WHO), the United Nations Environment Programme (UNEP) and the International Programmes on Chemical Safety (IPCS) (Zalk et. al, 2008). The collaboration resulted in a development of the ILO Chemical Control Toolkit which is based on COSHH Essentials, intended for use internationally and can be accessed on the ILO website (Alli, 2008). On the other hand, Stoffenmanager was one of such CB tools which was first launched in 2002 and has been approved by the Dutch Labor Inspectorates as a validated reliable tool to assess both inhalation and dermal risks (Marquart H, et. al, 2008).

CB in Malaysia started as early as 2009 when a group of DOSH officers attended a workshop on CB held in Kuala Lumpur by a consultant. Ever since then, the Malaysian government through the DOSH tried to review thoroughly the risk assessment method available and make a comparison between all the available CB models. DOSH started to draft the method called Simple Risk Assessment and Control (SiRAC) in 2009 by benchmarking both COSHH Essentials version at that time and the Stoffenmanager. Finally, a pilot study was conducted in 2009 to test the CB approach developed. The tool developed was piloted at few workplaces among states DOSH officers as well as among the industries. Training were also given to selected personnel on the checklist developed to test its applicability and usability. The development of SiRAC in Malaysia is shown in Figure 2. 


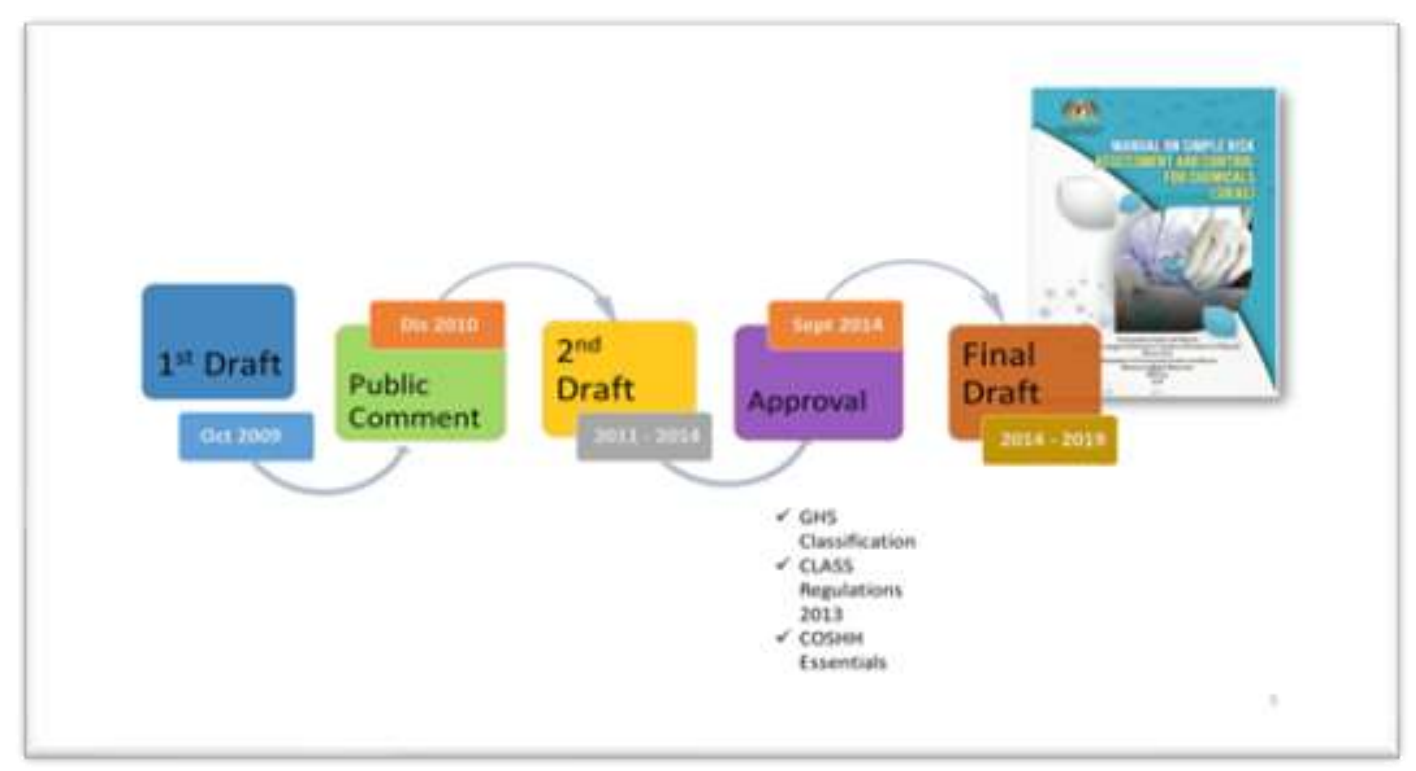

Figure 2. Development of SiRAC Malaysia

\subsection{MATERIAL AND METHODS}

\subsection{Research Aims and Objectives}

This research aims to contribute an added knowledge to the occupational safety and health practitioners, DOSH officers, academia and the public at large about the evolution of CB and the integration of CB in SiRAC in Malaysia. The SiRAC tool was launched in September 2019 after almost ten years since the initial drafting started. The long awaited tool had to go through the twists and turns of changes of hazards classification from the European Union (EU) classification in the Classification, Packaging and Labelling Regulations 1997 to the Globally Harmonised Systems (GHS) classification embedded in the existing regulations i.e. Classification, Labelling and Safety Data Sheets of Hazardous Chemicals (CLASS) Regulations which was gazetted in 2013. The SiRAC tool has been developed to provide practical guidance and advice for compliance to employer's duties under Section 15 (1) and Section 15(2) of Occupational Safety and Health Act 1994 and for compliance with the duty of employers to conduct chemical health risk assessment under provision 9 of the Use and Standard of Exposure of Chemicals Hazardous to Health (USECHH) Regulations 2000 (Department of Occupational Safety and Health Malaysia, 2019). SiRAC is different from the COSHH Essentials in its scope of coverage due to differences of legislations in the United Kingdom and Malaysia. Chemicals such as pesticides, veterinary medicines, lead, asbestos, and environmental effects of hazardous substances are not covered by the COSHH Essentials. In summary, COSHH does not cover chemicals which are already covered by other separate legislations.

\subsection{What is SiRAC?}

SiRAC is an alternative tool for conducting a chemical health risk assessment. It is a simplified methodology involving a process of grouping workplace risks into control bands based on combination of hazards and exposure information. It is adopting the "CB" approach where "bands" of hazards are combined with "bands" of exposure potential. The COSHH Essentials and the ILO Toolkit were initially developed for the SMEs. Similarly, in Malaysia, the target audiences are SMEs; as they are the vulnerable group lacking of resources to comply to legal provisions and SiRAC fits well as a simple assessment tool which does not require expert involvement. Unlike the USECHH regulation which applies to a wide range of chemicals hazardous to health, SiRAC method only applies to chemicals hazardous to health in the solid and liquid forms which are supplied for use at the workplace. These supplied chemicals are also regulated under the CLASS Regulations 2013 where they should be supplied with proper labels and safety data sheets (SDS). This Malaysian tool however, has its limitations. SiRAC is not applicable to the following chemicals even though they are covered under the USECHH Regulation. The chemicals or process are:

(1) Chemical classified as carcinogenicity category 1 , mutagenicity category 1 or respiratory sensitization category 1 under CLASS Regulations;

(2) Process generated dusts and fumes (e.g. wood dusts, fume released from molten metal);

(3) Naturally occurring hazards such as organic dust, e.g. grain dust, cotton dust and paddy husk dust; 
(4) Gases, such as. hydrogen sulphide, ammonia, etc.; and

(5) Scheduled waste as listed in the First Schedule under the Environmental Quality (Scheduled Wastes) Regulations 2005

The two most significant routes which are covered under SiRAC are inhalation and dermal while less significant routes such as ingestion and injection will not be covered in the assessment.

\subsection{Steps In Conducting Assessment}

Steps in conducting SiRAC assessment diferred from the full CHRA. Information required for the assessment are hazard classifications of chemicals and its hazard statement (H-code), physical forms of the chemicals, boiling point or vapour pressure for liquid, operating temperature of chemicals, total quantity of chemicasl used and the total duration of exposure to the chemicals. The assessment requires users who are the employers of the SMEs or any workplace to complete the seven steps that culminate in the identification of the task-specific controls (Figure 3).

\section{Steps To Conduct SIRAC}

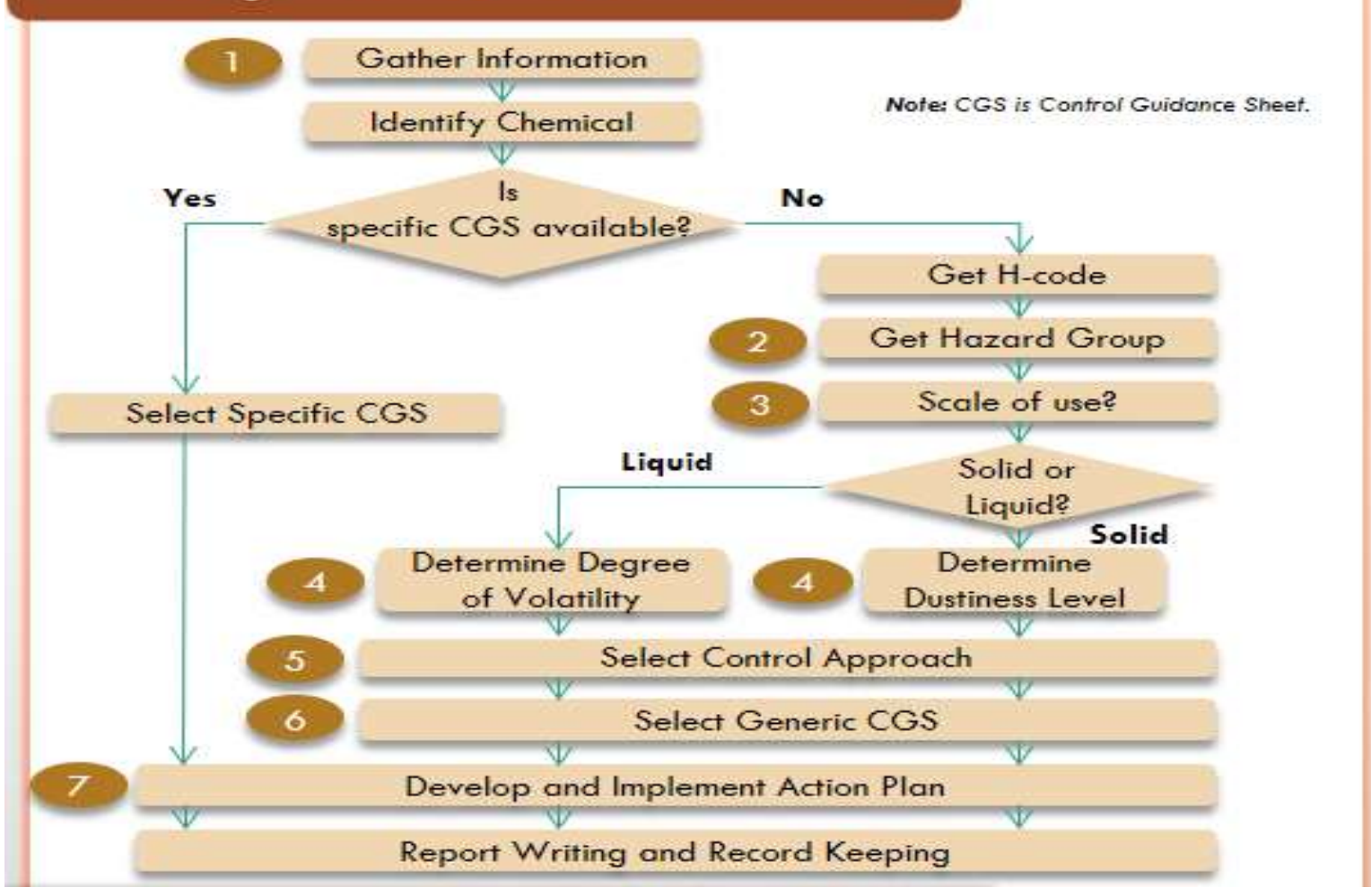

Figure 3: The seven steps of SiRAC (Department of Occupational Safety and Health Malaysia, 2019).

There are seven steps in conducting the assessment. During the first step of gathering information, the assessor can obtain information about the chemicals, task and processes involved from various sources such as workplace chemical register, SDS, label, plant manual, plant layout, process flow and the number of personnel involved in the tasks involving chemicals. Hazard classification and relevant hazards statements can be obtained from the SDS. The hazards classifications as regulated under the OSH CLASS Regulations 2013 are based on the Globally Harmonised System of Classification and Labelling of Chemicals Third Revised Edition 2009 (Department of Occupational Safety and Health Malaysia, 2014), provides the hazard indication corresponding to the categories of hazards by using hazards statements, hazards pictogram, precautionary statements and hazard codes (H-code). Table 1 and Table 2 represents the corresponding hazard bands or groups with $\mathrm{H}$-code to be used by assessor for reference during assessment. 
Table 1 Corresponding Hazards Groups and H-code

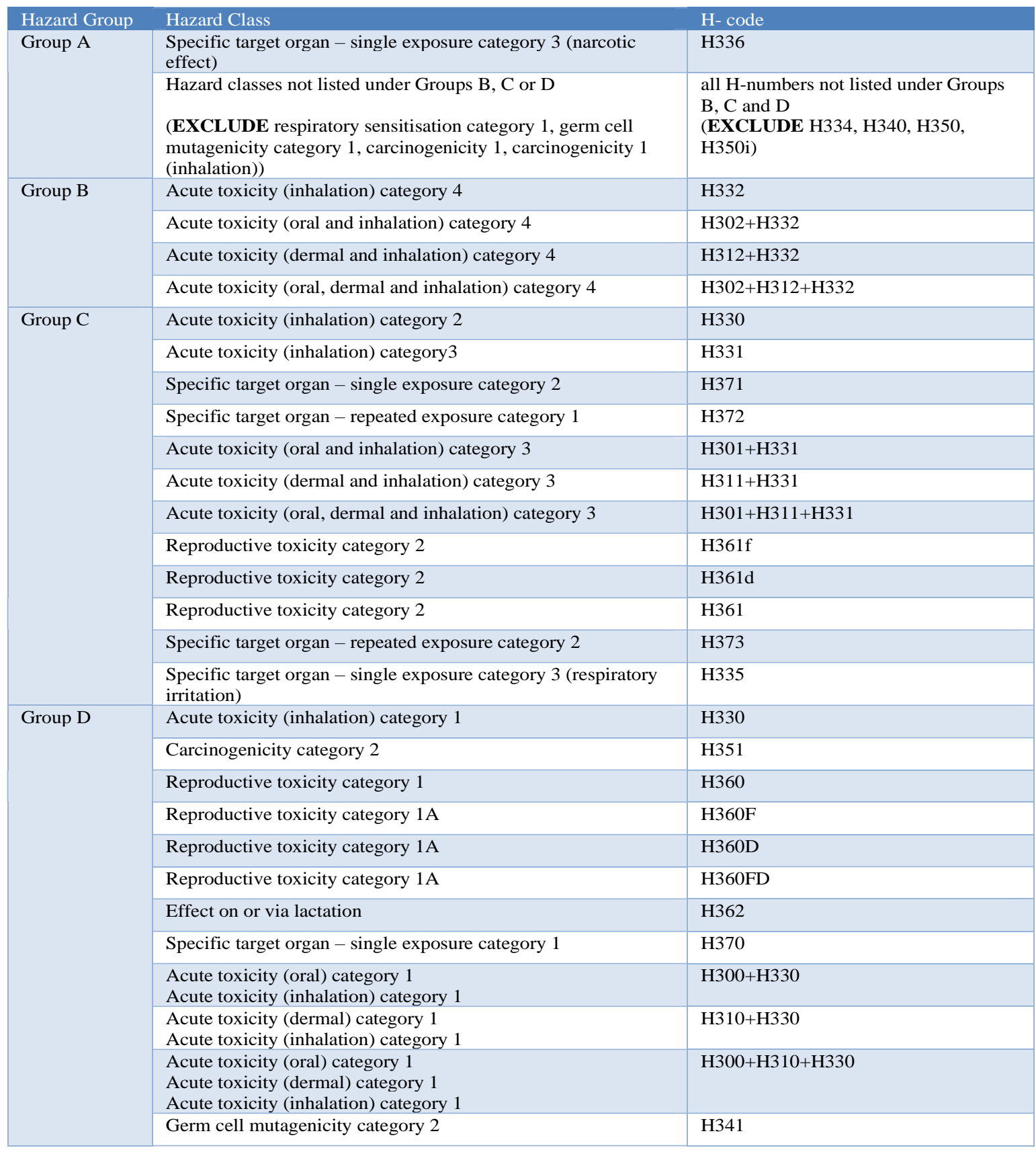

Under step 2, assessor needs to also check hazard group $\mathrm{S}$ besides hazard groups A to D. Hazard group $\mathrm{S}$ (Table 2) refers to hazards associated with skin and eyes when workers are exposed to these chemicals. 
Table 2: Hazard groups S (chemicals causing harm in contact with skin and eyes

\begin{tabular}{|c|c|}
\hline Hazard class & H- code \\
\hline Acute toxicity (dermal) category $1 \&$ category 2 & H310 \\
\hline Acute toxicity (dermal) category 3 & H311 \\
\hline Acute toxicity (dermal) category 4 & H312 \\
\hline Skin corrosion or irritation category 2 & H315 \\
\hline Skin corrosion or irritation category 1 & H314 \\
\hline Skin sensitisation category 1 & H317 \\
\hline Serious eye damage category 1 & H318 \\
\hline Serious eye damage category 2 & H319 \\
\hline $\begin{array}{l}\text { Acute toxicity (oral) category } 1 \& \text { category } 2 \text { and } \\
\text { Acute toxicity (dermal) category } 1 \& \text { category } 2\end{array}$ & $\mathrm{H} 300+\mathrm{H} 310$ \\
\hline $\begin{array}{l}\text { Acute toxicity (dermal) category } 1 \& \text { category } 2 \text { and } \\
\text { Acute toxicity (inhalation) category } 1 \& \text { category } 2\end{array}$ & $\mathrm{H} 310+\mathrm{H} 330$ \\
\hline $\begin{array}{l}\text { Acute toxicity (oral) category } 1 \& \text { category } 2 \text {; } \\
\text { Acute toxicity (dermal) category } 1 \& \text { category } 2 \text { and } \\
\text { Acute toxicity (inhalation) category } 1 \& \text { category } 2\end{array}$ & $\mathrm{H} 300+\mathrm{H} 310+\mathrm{H} 330$ \\
\hline $\begin{array}{l}\text { Acute toxicity (oral) category } 3 \text { and } \\
\text { Acute toxicity (dermal) category } 3\end{array}$ & $\mathrm{H} 301+\mathrm{H} 311$ \\
\hline $\begin{array}{l}\text { Acute toxicity (dermal) category } 3 \text { and } \\
\text { Acute toxicity (inhalation) category } 3\end{array}$ & $\mathrm{H} 311+\mathrm{H} 331$ \\
\hline $\begin{array}{l}\text { Acute toxicity (oral) category } 3 \text {; } \\
\text { Acute toxicity (dermal) category } 3 \text { and } \\
\text { Acute toxicity (inhalation) category } 3\end{array}$ & $\mathrm{H} 301+\mathrm{H} 311+\mathrm{H} 331$ \\
\hline $\begin{array}{l}\text { Acute toxicity (oral) category } 4 \text { and } \\
\text { Acute toxicity (dermal) category } 4\end{array}$ & $\mathrm{H} 302+\mathrm{H} 312$ \\
\hline $\begin{array}{l}\text { Acute toxicity (dermal) category } 4 \text { and } \\
\text { Acute toxicity (inhalation) category } 4\end{array}$ & $\mathrm{H} 312+\mathrm{H} 332$ \\
\hline $\begin{array}{l}\text { Acute toxicity (oral) category } 4 \text {; } \\
\text { Acute toxicity (dermal) category } 4 \text { and } \\
\text { Acute toxicity (inhalation) category } 4\end{array}$ & $\mathrm{H} 302+\mathrm{H} 312+\mathrm{H} 332$ \\
\hline
\end{tabular}

Step 3 to step 6 of the assessment are simpified in Table 3 where assessor needs to decide scale of chemicals used and to determine liquid volatility or the dust's level of dustiness.

Table 3: Step 3 to step 6 of SiRAC method

\begin{tabular}{|l|l|}
\hline Steps & Description \\
\hline Step 3: Scale of chemical use & Volume of chemicals used: small, medium or large \\
\hline Step 4: Ability to become airborne & $\begin{array}{l}\text { Volatility of liquids are based on boiling point and operating temperatures: low, } \\
\text { medium or high. For solids, level of dustiness is used giving either low, medium } \\
\text { or high level of dustiness. }\end{array}$ \\
\hline Step 5: Control Approach & $\begin{array}{l}\text { Answers from Steps 3 - 4 are used with a matrix of Control Approach } \\
\text { Selection to identify the appropriate control approach: } \\
\text { (i) general ventilation; (ii), engineering control; (iii), containment; or (iv), } \\
\text { specialist advice }\end{array}$ \\
\hline Step 6: Task-specific guidance & $\begin{array}{l}\text { The control approach level from Step 5 is used to identify a guidance sheet } \\
\text { for the specific task in which the substance is used }\end{array}$ \\
\hline
\end{tabular}

For specific chemical tasks involving cleaning, pest control or lithography printing, one does not need to go through steps 2 to step 6 when conducting the assessment. These specific tasks will direct the assessor to use the specific CGS as listed in Table 4. Assessor needs to select control guidance sheets (CGS) either Generic CGS or Specific CGS by using Table 4 according to the tasks description involved. 
Table 4: Types of Control Guidance Sheets (Generic or Specific)

\begin{tabular}{|l|l|}
\hline Generic Control Guidance Sheets & Specific Control Guidance Sheets \\
\hline G Series & Cleaning Services -C001- C006 \\
CA1: G100-G103 & \\
CA2: G200-G231 & \\
CA3: G300-G322 & Pest Control - P001- P007 \\
\hline S Series - S100, S101, S102 & Lithography Printing- LP001-LP006 \\
\hline R Series- R001 & \\
\hline
\end{tabular}

Under step 7, the assessor needs to compare advice given in the CGS with the current practices including the existing control measures in place, procedures and work practices. The decision has to be made on suitability and the practicality of the control approach selected. From the results of the assessment and the comparison made, an action plan consisting of improvements to be made, recommended further controls and other measures to be taken to comply to the USECHH Regulations has to be presented to the employer or owner of the workplace.

\subsection{DISCUSSIONS}

As highlighted in paragraph 2.2, SiRAC method has its limitation where it is not applicable to certain chemicals and hot processes forementioned. These processes could be too complex that might require additional considerations not yet fully addressed by CB. Nevertheless, an assessor needs to conduct full assessment for those complex processess and chemicals not covered by SiRAC using the manual for full CHRA Third Edition 2018. SiRAC tool does not consider occupational exposure limit in the assessment, hence it is a very useful tool for assessing and controlling occupational hazards in the absence of occupational exposure limits (Stephanie Chalupka, 2011). The steps in conducting assessment in SiRAC is found to be almost similar to the steps in the UK COSHH Essentials. The assessment in Malaysia should be done by a competent person registered with the Director General of DOSH or any trained person who has completed training at any DOSH approved training centre while any employer can do the assessment under the UK COSHH. It should be emphasized that the control guidance sheets available for specific tasks in the UK COSHH Essentials are greater than the numbers of CGS which SiRAC Malaysia has for its specific CGS.

\subsection{Advantages and limitations of SiRAC}

It has been demonstrated that by conducting SiRAC at workplace, an employer is deemed to have complied with the provision of conducting risk assessment under regulations 9 of the USECHH Regulations. This assessement also helps to prevent workers from over exposure to chemicals hazardous to health at work by modifying the way task is carried out, modifying process involving exposure to chemicals, proposing new safe work procedures and finally adequately controlling or reducing exposure to those chemicals.

To identify adequate controls, SiRAC uses two factors. The factors are the type of harm the chemical can cause and the amount needed to cause it; and how much chemicals is likely to get into the air, be breathed in, or come into contact with their skin or eyes which in turn depends on the amount being used, its dustiness (for solid) or volatility (for liquid) and total duration of exposure (Department of Occupational Safety and Health Malaysia, 2019).

SiRAC recommends four groups of control named as control approaches. The control approaches are general ventilation, engineering control, containment and specialist advice. Each control approach covers a range of actions that work together to complement reducing exposure to chemicals named as CGS. The actions in the CGS are good plant and equipment design; regular housekeeping and cleaning; regular maintenance, examination and testing of equipment; worker training and supervision; and personal protective equipment (PPE). There are two types of CGS namely Generic CGS and Specific CGS. The Generic CGS is arranged according to the control approach it covers. It includes general sheets, more detailed sheets with recommendations on good practice control and supplementary sheets on avoiding skin and eye contact with chemicals and on selecting and using PPE.

The person to conduct SiRAC should undergone SiRAC training programme by the DOSH's approved training provider. Since its launching in September 2019, information on workplace which has been assessed using SiRAC method has been negligible or scarce. In Malaysia, full assessment is conducted by a competent Chemical Risk Assessor. During this transition, the competent assesor can conduct the SiRAC as illustrated in Figure 4. 


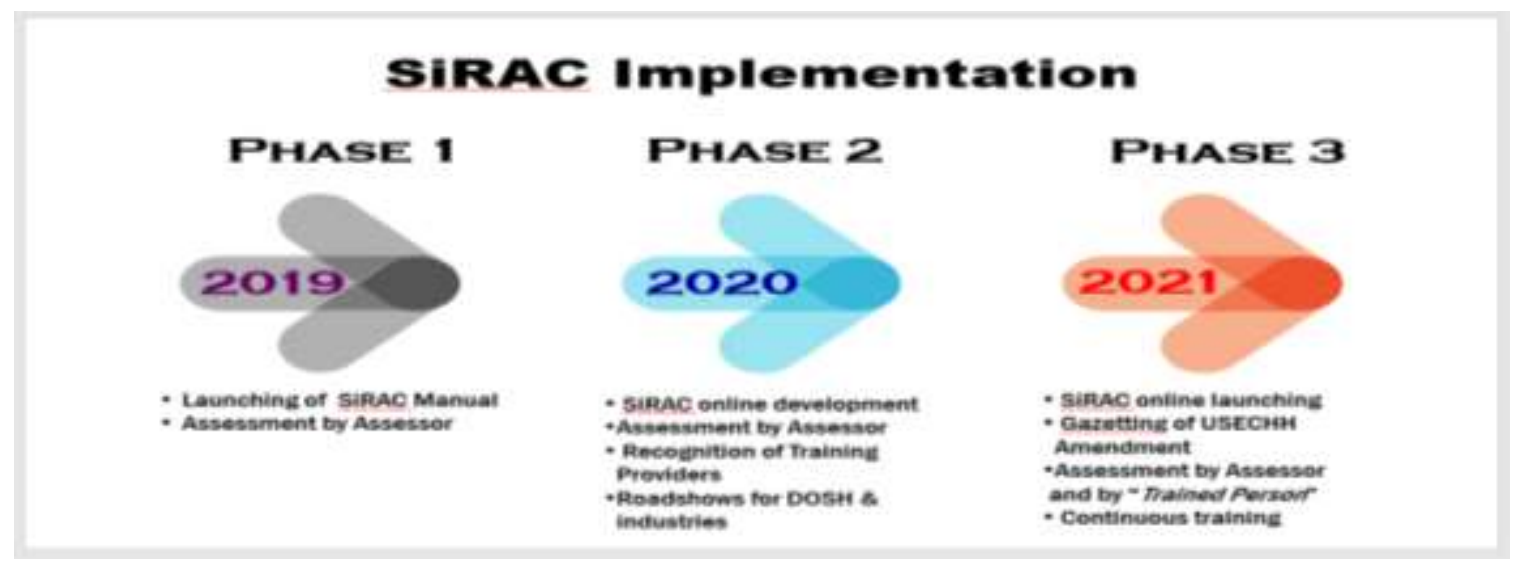

Figure 4 Three phases of SiRAC implementation during the transition period in Malaysia.

\subsection{Margin of Safety Provided by SiRAC}

Operational analysis of CB tools has been scantily represented in many published literatures. It is important to determine if the intended users are able to use and prepare complete reliable risk assessment and subsequently select the appropriate control measures. Since SiRAC Malaysia is benchmarking the United Kingdom's COSHH Essentials (Health and Safety Executive, 2020), Stoffenmanager (Stoffenmanager, 2020) and the ILO Toolkit (International Labor Organization, 2020), literatures on these tools are looked upon as a reference for future improvements.

Few published literatures on extensive usability of the internet based COSHH Essentials found that the intended users were confused by the tool's focus on tasks or activities rather than the chemicals; confused by the structure and interface of the said tool as well as the lack of coverage for not catering for users of different levels of knowledge (Cope M., 2007). Some literature suggested to provide an improved guidance and training before using the assessment tool. Some literature further concluded that it is important for the intended users to understand the limitations of any tools in term of ouput and its applicability (Lamb J, Crawford JO, Davis A, Cowie H, Galea K, Van Tongeren M. , 2014).

Published literatures also suggested that the existing ILO Toolkit provides better safety margin than the COSHH Essentials i.e. more protective of the workers' health (Jones R. M. \& Nicas M., 2006). SiRAC on the other hand has been piloted in the field and has been validated among industry players. However, the control measures recommended under SiRAC tool has not been compared with those obtained from the full chemical health risk assessment yet for its appropriateness. Nor has it been analysed for operational implementation since it is recently introduced.

Figure 4 highlighted about the government's decision to introduce an internet based online tool for SiRAC in 2021. Currently the SiRAC Online is under development and being reviewed to cater for the changes of the hazards classifications from the previous developed one. Despites its limitation and anticipated predicted weaknesses from various literature reviews on $\mathrm{CB}$ models, SiRAC is expected to assist SMEs to protect their workers from the exposure to chemicals hazardous to health at the workplace. Expert advice should be made available and easily accessed by the SMEs to enable SiRAC to be an outstanding added value to the risk management in the country.

\subsection{CONCLUSION}

The proposed risk assessment i.e. SiRAC is capable in helping intended users on decision making to consider the appropriate control selection. Based on the result of the assessment, the users can identify appropriate CGS based on the selected tasks with hazard groups of chemicals used at work. Further study can be carried out to take into account the number of industries using the SiRAC tool. Data collected is useful for further profile studies. Comparison study between the appropriateness of the control banding judgement and full assessment can then be conducted. An economic study on control measures recommended through CB judgement would be a useful information to all SMEs in Malaysia in adopting SiRAC as an alternative tool for risk assessment. SiRAC tool is expected to be sufficient as an initial tool complemented with SiRAC Online to assist SMEs in chemical risk management.

\section{References}

[1] ILO. 2020. International Labor Organization. Retrieved from International Labor Organization Web site: https://www.ilo.org/global/industriesand-sectors/chemical-industries/lang--en/index.htm Access date: 21 November 2020 
[3] Cope M. 2007. Human factors/usability evaluation of the internet based electronic COSHH-essentilas system. Report no: HSL/2007/60. Derbyshire (UK): Health and Safety Laboratory, Buxton.

[4] Department of Occupational Safety and Health. 2020. Get Rich with Lower Risks for Higher Returns. Business in Action @ FMM, 22-23.

[5] Department of Occupational Safety and Health Malaysia. 2014. Industry Code Of Practice On Chemicals Classification and Hazard Communication. Kuala Lumpur: Department of Occupational Safety and Health, ISBN 978-983-2014-78-2.

[6] Department of Occupational Safety and Health Malaysia. 2019. Manual On Simple Risk Assessment and Control For Chemicals (SiRAC) 2019. Kuala Lumpur: DOSH ISBN 978-967-16706-1-3.

[7] Health and Safety Executive. 2020. HSE COSHH Essentials. Retrieved from Health and Safety Executive: https://www.hse.gov.uk/coshh/essentials/index.htm Access date: $31^{\text {st }}$ December 2020

[8] International Labor Organization (2020). World Statistics: The enormous burden of poor working conditions. Retrieved from International Labor Organization: $\quad$ https://www.ilo.org/moscow/areas-of-work/occupational-safety-and-health/WCMS_249278/lang-en/index.htm\#: :text=The\%20ILO\%20estimates\%20that\%20some,of\%20work\%2Drelated\%20illnesses\%20annually. Access date: 26th December 2020

[9] International Labor Organization. 2020. ILO International Chemical Control Toolkit. Retrieved from International Labor Organization: https://www.ilo.org/legacy/english/protection/safework/ctrl_banding/toolkit/icct/index.htm Access date: $31^{\text {st }}$ December 2020

[10] Jones R. M. \& Nicas M. 2006. Margins of Safety Provided by COSHH Essentials and teh ILO Chemical Control Toolkit. Ann. Occupational Hygiene 50(2): 149-156.

[11] Khoo T.H. et. al. 2011. Occupational Safety and Health (OSH) in Malaysian Small and Medium Enterprise and Effective Safety Management Practices. Intemational Journal of Business and Technopreneurship, 1(2): 321-339.

[12] Lamb J, Crawford JO, Davis A, Cowie H, Galea K, Van Tongeren M. 2014. Report on between-user reliability exercise (BURE) and Workshop. Institute of Occupational Medicine, 220.

[13] Marquart H, et. al. (2008). "Stoffenmanager", a web-based control banding tool using an exposure process model. Ann Occup Hygiene, 429-41.

[14] SME Corp. (2020.. SME Corp Malaysia. Retrieved from SME Corp Web Site: https://www.smecorp.gov.my/index.php/en/policies/2020-02-1108-01-24/sme-definition Access date: $21^{\text {st }}$ November 2020

[15] Stephanie Chalupka. (2011). Control Banding for Risk Management of Source Chemical Agents and Other Occupational Hazards. American Association of Occupational Health Nurses, Inc, 404.

[16] Stoffenmanager. 2020. What is Stoffenmanager@R . Retrieved from Stoffen Manager8: https://stoffenmanager.com/what-is-stoffenmanager/ Access date: $31^{\text {st }}$ December 2020

[17] Zalk DM \& Nelson DI. (2008). History and evolution of control banding: A review. Journal of Occupational and Environmental Hygiene. 5(5): $30-46$ 